\title{
Critical Thinking: Apply It to Global Pollution!
}

\author{
J. T. Trevors
}

Published online: 11 November 2010

(C) Springer Science+Business Media B.V. 2010

The art and science of critical thinking (i.e., improving the quality and quantity of thinking by using intellectual standards) should be applied when addressing the problems, challenges, and crises resulting from global pollution. Humans will then be able to improve the quality and content of their thinking. This is achieved by skillfully thinking and imposing intellectually demanding standards upon themselves and each other that lead to the correct or best answers, accords, agreements, laws, solutions, policies, and hypotheses for further experimentation. Critical thinking requires that humans have the capacity to self-correct their self-directed thinking. The thinking should not be fragmented, bias, incomplete, and closed minded. The evidence and knowledge must be the best available, and if not available, new knowledge will be necessary through research, observations, and experimentation.

Critical thinking is an asset in clarifying interconnected problems, identifying correct and achievable goals, evaluating sources of information, and arriving at the best solutions to complex problems, being able to defend solutions and sustain our common, shared, singular biosphere. With a current human population of about 6.7 billion people, over 1 billion without the basic needs of

J. T. Trevors $(\bowtie)$

School of Environmental Sciences, University of Guelph, Guelph, ON N1G 2W1, Canada

e-mail: jtrevors@uoguelph.ca life, and the population increasing at about $75-80$ million people annually, critical thinking must be employed by all people. This will assist in protecting, conserving, and improving our biosphere from too many humans and too much global pollution. Critical thinking applied by all people (especially the so-called world leaders) to our environment will assist humanity by seeking the best knowledge, being well informed, using credible sources of knowledge, visualizing the total situation, seeking better and correct alternatives, changing ideas where necessary, and seeking superior solutions as new knowledge becomes available.

Critical thinking applied to our priority global challenges will enable humans to focus on the challenges/crises, listen to and analyze the debates and positions taken by countries and organizations, be able to judge the credibility of the knowledge sources, and plan and implement actions while interacting internationally and acting in the interest of our global community. This will of course require some intellectual and scholarly activities on behalf of the representatives at international meeting and all citizens of the planet Earth. Since humans use thinking as the means to make sense of the world, all humans must know how to critically think to arrive at the correct conclusions and actions. Otherwise, thinking is often bias, uninformed, discriminating, incorrect, and selfish, leading to a very poor quality of life and more pollution of our planet. The thinking process applied to global pollution must be purposeful, using correct data, facts, experiences, concepts, and theories. 
Humans must understand what the purpose of their critical thinking is. Are their assumptions correct? What additional information and knowledge are needed to answer the major and minor questions? Some humans will not even know or understand why they are or should be thinking about such problems/ challenges. Some humans do not know what they do not know, nor do they know what they need to know. Some people who have been formally educated in schools, colleges, and universities fail to think in a critical manner. They often think in an incorrect or flawed historical context based on outdated information, beliefs, and ignorance. One can also add greed, power, control, fraud, and corruption.

What to do? Critical thinking applied to our global pollution and uncontrolled human population growth will raise the correct issues and solutions, set intellectual standards that must be met when negotiating international binding agreements and communicate the issues and correct answers to interconnected complex answers in a respectful manner. The roles of education and critical thinking in solving our common biosphere crises should not be overlooked or underestimated. It is not all about human-made economic systems, economic wars, economic growth and protectionism. Critical thinking should lead humans to the correct conclusion that creating global pollution and overpopulating the planet, and then seeking economic type solutions is not rationale or logical. Human brains that were not critically thinking created the problems, and now, critically thinking human brains will have to solve the problems. 